\title{
HISTÓRIA E TEATRO EM TRINDADE-GO: DO BARRO PRETO À RUA DA ALEGRIA
}

\section{HISTORY AND THEATER IN TRINDADE-GO: FROM BARRO PRETO}

TO RUA DA ALEGRIA

Walquiria Pereira Batista*

RESUMO: Com o presente artigo, pretendemos estudar como o Grupo da Villa de Barro Preto de de Goyaz e Rua da Alegria-GO nas pecas Povo vida, trazendo à bila a noção de representaça como ponto comum vo , tre vo teatro da historia cultral, inseprindo, nesse mesmo raciocío, capro cão do Grupo Desencanto de Teatro, realizapos us uma anelise dram túrgica dos Despéculos em estudo colizaremos uma anáficar como recon

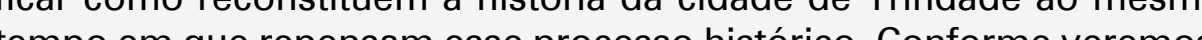
tempo en que repisutem condutes e valores, ora questionando lís, res poltios e riscutem condutas e valores, ora questonáno lidefes pollicos e religiosos consagrados pela histón do municio, ora forlo

PALAVRAS-CHAVE: História; teatro; Trindade-GO. *walb_gyn@yahoo.com.br

Mestre em Filosofia pela Universidade Federal de Goiás. Professora da Escola de Música e Artes Cênicas da UFG.

ABSTRACT: With the present article, we try to study how the Theater Disenchantment Group (Grupo Desencanto de Teatro) recreates the history of TrindadGiás in the plays People of the Black Clay Village hist Goyz (Povo da Villa de Barro Preto de Goyaz) and Street Of Joy (Rua daz (Povo da Vills in the plays People of the Black Clay Vila Joy cating from what perspective we will relate art and life, presenting the cation of represention history, ine question of the urban world of imagination. After a short present the of the Theater Disen world of imagination. After a short presentation and analysis of the plays under study, wh, whe will make a draming they rethink this historical pros. As we are going to see both works discuss conduct and values, sometimes questioning political and

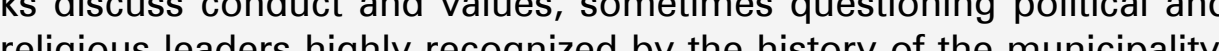
religious leaders highly recognized by the history of the municipality, sometimes focusing on a group of women who have been excluded

KEYWORDS: History; theaer; Tindade-Goias. 
1. Aristóteles. Poética, p. 209 [Cap. IX, §50].

2. Aristóteles. Poética, p. 209 [Cap. IX, §50].

\section{ARTE \& VIDA, UMA REFLEXÃO À GUISA DE}

\section{PREÂMBULO}

Relacionar arte e vida sempre foi objeto de especulação de pensadores desde tempos imemoriais. Para recorrer a um cânone da estética ocidental, podemos aludir a Aristóteles, cujas ideias registradas em sua Poética fazem uma conhecida distinção entre poesia e história. Em uma emblemática passagem da seção IX, o filósofo declara "que não é ofício de poeta narrar o que aconteceu; é, sim, o de representar o que poderia acontecer, quer dizer: o que é possível segundo a verossimilhança e a necessidade". Por isso, a poesia é, para o pensador estagirita, "algo de mais filosófico e mais sério do que a história, pois refere aquela principalmente o universal, e esta o particular". ${ }^{2}$ Dessa perspectiva, a poesia conta com um material infindável, inacessível à história, visto que o trabalho do poeta, em sua composição métrica, consiste não na preocupação de relatar um evento que ocorreu, mas, antes, em imitar uma ação que seja aceita como possível.

Cremos que essa noção aristotélica de poesia está muito mais próxima do conceito fundador da história cultural, qual seja, o de representação, do que da noção clássica de história legada pelo filósofo grego. Isso porque, naquela nova forma de interpretar a realidade, a história é entendida como recriação do real, não como narração mimética do
BELO HORIZONTE
N. 1

JAN.-ABR. 2018 acontecido. Nessa concepção, como afirma a historiadora Sandra Pesavento, "A História Cultural se torna, assim, uma representação que resgata representações, que se incumbe de construir uma representação sobre o já representado". Sob esse prisma, discursos, imagens, ritos e práticas de natureza variada são representações às quais se volta o historiador, que as estuda como formas de ler uma realidade e o modo como esta foi pensada. Com isso, ele tece uma narrativa que está mais perto de uma "ficção controlada". Segundo Pesavento,

Nesta medida, a força das representações se dá não pelo seu valor de verdade, ou seja, o da correspondência dos discursos e das imagens com o real, mesmo que a representação comporte a exibição de elementos evocadores e miméticos Tal pressuposto implica eliminar do ca mpo de análise a tradicional clivagem entre real e não real, uma vez que a representação tem a capacidade de se substituir à realidade que representa, construindo o mundo paralelo no qual as pessoas vivem. ${ }^{5}$

O tea tro é, como forma de arte, uma representação, especialmente quando se propõe a ser, tal como concebem os clássicos, para retornar a Aristóteles, uma imitação de ação humana. Nessa linha de pensamento, em um jogo de palavras, poderíamos afirmar que o teatro, com a linguagem
Pesavento História \& históri cultural, p. 43.

4. Pesavento. História \& história cultural, p. 58.

5. Pesavento. História \& história cultural, p. 41. 
que lhe é característica, é a arte que dá vida ao vivo a um acontecimento vivido. Assim, essa arte se revela ao historiador cultural como prática artística que, com cenário, iluminação, sonoplastia, texto, figurinos, atores, maquinistas e contra rregras, tem a capacidade de presentificar histórias, na fugacidade do "aqui e agora" do espetáculo. Com os seus diferentes signos, o teatro denuncia épocas, lugares, pessoas, fatos, conflitos, costumes, crenças, valores etc., legitimando ou contestando a(s) história(s) que nos contaram. Nesta pesquisa, interessa-nos verificar como o tea tro pode recontar as histórias de uma cidade, aqui vista como campo de pesquisa da história cultural.

Nesse ponto, é preciso notar que a cidade como campo da história cultural passa por uma nova abordagem, que não é a da história oficial dos livros ou dos arquivos institucionais, voltada para questões de ordem política, econômica ou social, pautada por dados estatísticos. Diversamente, conforme sustentam os pesquisadores Emerson Campos e Luiz Felipe Falcão, esse novo olhar da história busca, antes ultrapassar as histórias que foram legitimadas pela hegemonia "com a incorporação do esquecido, do menosprezado, do estigmatizado, do derrotado, mostrando outros ângulos de uma trajetória apresentada quase sempre a partir de uma única ótica, homogênea e uniformizadora". ${ }^{6}$ A propósito, mesmo fora da visão da história cultural, a cidade é reconhecida como objeto complexo, considerando os seus vários sujeitos, relações e instituições na produção do espaço urbano, como conclui, sobre o conceito de cidade, o geógrafo Tadeu Arrais, no seu livro Seis modos de ver a cidade:

Arte, técnica, cultura, religião, rebelião e política são atividades que necessitam, para o seu pleno desenvolvimento, do agrupamento de pessoas. Do olhar público. Quando percebemos que tudo isso, somado às necessidades de reprodução da vida diária, é feito em um sítio comum, começamos a entender o significado da palavra 'cidade'. Um conceito polissêmico. Mas a polissemia não deve nos desviar da ambição de pensar sobre ele, submetendo-o à nossa experiência cotidiana. Se a cidade não é só pedra, concreto e madeira, é justa mente porque o homem não é apenas carne, sangue e suor.

De sua parte, à história cultural interessa compreender as representações que ocorrem na e sobre a cidade, e estudar como tais representações povoam o imaginário urbano. Busca-se examinar a cidade como espaço de trocas simbólicas nos seus diferentes lugares, como ruas, praças, pontes, becos, viadutos, escolas, casas, prédios, mercados, córregos etc., atentando para o que esses espaços revelam de seus cidadãos, seus anseios, receios e conflitos. Para além do que indicam conhecimentos de cartografia, topografia e densidade demográfica, trata-se de perceber cada espaço do lócus
7. Arrais. Seis modos de ver a cidade p. 155; grifo do autor. 6ampos; Falcão. Percorrendo cidades na contemporaneidade, $\mathrm{p}$. 92.
EM TESE
BELO HORIZONTE
N. 1

JAN.-ABR. 2018

BATISTA. História e teatro em Trindade-GO [...]

P. $174-189$ 
8. Pesavento. História \& história cultural, p. 77-78.

9. Pesavento. Muito além do espaço: por uma história cultural do urbano, p. 281; grifo da autora. citadino como discurso, portanto texto interpretado pelos seus sujeitos, os quais, com as suas práticas, consagram ou subvertem a locução oficial. Sobre esse campo de investigação da história cultural, a historiadora Pesavento esclarece que

O que cabe destacar é a abordagem introduzida pela História Cultural: ela não é mais considerada só como um locus, seja da realização da produção ou da ação social, mas sobretudo como um problema e um objeto de reflexão. Não se estudam apenas processos econômicos e sociais que ocorrem na cidade, mas as representações que se constroem na e sobre a cidade. Indo mais além, pode-se dizer que a História Cultural passa a trabalhar com o imaginário urbano, o que implica resgatar discursos e imagens de representação da cidade que incidem sobre espaços, atores e práticas sociais.

A paisagem de uma cidade diz muito de seus moradores e de suas memórias, ao mesmo tempo em que estes, com as suas práticas, interferem diretamente na paisagem urbana. Em vista disso, na mesma esteira de Pesavento "Nosso intento é, pois, resgatar a cidade como real através da 'leitura da cidade', ou de suas representações. [...] partir do pressuposto de que as representações são parte integrante também daquilo que chamamos realidade". ${ }^{9}$ Nesse "resgate", o tea tro dá a ler e a ver o real porque a nima texto e imagem, como diz a citada historiadora no livro História es história cultural: "Da pintura ao cinema, da história em quadrinhos à fotografia, do desenho à televisão, tais imagens povoam a vida e a representam, [...]. Que dizer, então, do teatro, que não só dá a ver como dá a ler, além de encenar, ao vivo e em cores, aquilo que apresenta ao espectador?”. ${ }^{10}$

Com base na temática aqui proposta, o presente artigo busca fazer uma relação entre realidade e ficção, uma vez que pretende examinar, a partir da linguagem teatral, abordagens da história e da cultura de Trindade, diversa mente de uma perspectiva tradicional. O tea tro aqui é visto como representação que dá a ver episódios da história da cidade, compreendida em diferentes momentos, evidenciando fatos, conflitos, lugares e sujeitos inscritos na memória do município. Conforme veremos, a cidade de Trindade-GO é o próprio objeto de reflexão dos espetáculos Povo da Villa de Barro Preto de Goyaz e Rua da Alegria, os quais reconstituem a cidade de outrora, com os seus ranchos, igrejas, vendas e prostíbulos. Mas, antes disso, é preciso fazermos uma breve apresentação do Grupo Desencanto de Teatro, responsável pela dra maturgia e encenação das duas peças em questão.

\section{NOTAS SOBRE O GRUPO DESENCANTO DE TEATRO}

O Grupo Desencanto de Teatro foi fundado por Amarildo Jacinto, seu diretor artístico, no a no de 1986, e possui a sua sede na cidade de Trindade, localizada a 18 km de Goiânia.
10. Pesavento. História \& história cultural, p. 89.
EM TESE
BELO HORIZONTE
v. 24
N. 1
JAN.-ABR. 2018
BATISTA. História e teatro em Trindade-G0 [...]
P. $174-189$ 
11. Jacinto, "História", Jacinto et al. Grupo Desencanto de Teatro: especial 25 anos, p. 8.

12. Jacinto, "Venha para esse mundo de arte e cultura!", Jacinto et al. Grupo Desencanto de Teato
especial 25 anos, p. 3.

13. O Grupo Desencanto de Teatro adota a sigla GDT, a qual também utilizaremos em algumas passagens.

14. Cunha, "Apresentação", Jacinto et al Grupo Desencanto de Teatro: especial 25 anos, p. 6.

15. “O Grupo, ao longo dos anos, vem oferecendo à comunidade em geral aulas de ballet clássico, balle contemporâneo, dança de salão, dança do ventre, teatro, violão, piano, canto coral, pintura em tela e artesanato". Jacinto, "Escola de Artes", JACINTO et al. Grupo Desencanto de Teatro: especial 25 anos, p. 7.
O propósito do grupo era, inicialmente, movimentar culturalmente o lugar, com a apresentação de espetáculos que a mbicionavam excursionar por todo o país, como relata Jacinto na revista Grupo Desencanto de Teatro: especial 25 a nos. Entretanto, isso não foi possível em um primeiro momento, dada a dificuldade de se encontrar pessoas dedicadas ao teatro, e precisamente por isso "O grupo começou a fazer arte para a própria comunidade para, dessa forma, preparar quem desejasse ser artista, dando a base de trabalhos artísticos e culturais que pudessem contribuir para o crescimento da estrutura cultural do meio em que vivemos". ${ }^{11}$

Com esse propósito, cabe chamar atenção para o nome do grupo, pois como define o seu fundador, "O Desenca nto é o despertar do encanto". ${ }^{12}$ Sobre esse ideário de despertamento para a realidade, indica o atual presidente do GDT, ${ }^{13}$ Rodrigo Cunha, integrante do grupo desde criança: "O trabalho do Desencanto visa a utilizar a arte como instrumento para o desenvolvimento das percepções, emoções e inteligências múltiplas das pessoas, promovendo a visão crítica e questionadora tão necessária para a atual realidade e construção da cidadania”. ${ }^{14}$

Dissuadido do primeiro objetivo, em vista das precá rias condições com que se deparou, Jacinto começou a empregar todo o seu esforço na formação cultural e artística, criando a Escola de Artes do GDT. ${ }^{15}$ Ao mesmo tempo, desde fins da década de 1980, o diretor estreou uma série de atividades e eventos, que comporiam, posteriormente, o calendário anual do grupo, tais como a encenação da Vida, Paixão e Morte de Jesus Cristo, a Escola de Samba Acadêmicos de Trindade, ${ }^{16}$ às quais se somariam, a partir dos anos 1990 , o Festival de Artes ao Ar Livre ${ }^{17}$ e o Festival Estudantil de Teatro de Trindade; ${ }^{18}$ além disso, o grupo deu início a peças tea trais de repertório. A propósito, transcrevemos a seguinte referência do pesquisador de Trindade Amir Jacob, no ano em que o grupo tea tral completava treze anos de atividades:

Trindade conta hoje com excelente grupo de teatro amador - o Grupo Desencanto, que congrega cerca de 1200 participantes, a maioria jovens. Fundado há 13, por Amarildo Jacinto de Souza, o grupo teatral impõe-se no cenário estadual, não só pelo volume de participantes, como por promover a arte e a cultura em todos os setores. Em Trindade promovem festivais de arte, carnaval e fazem ainda a encenação da Paixão de Cristo, na Sexta-Feira Santa, ao longo da Rodovia dos Romeiros. ${ }^{19}$

Em meio a atividades artísticas tão diversificadas, o grupo começou, desde a década de 1990, a encenar espetáculos baseados em eventos e figuras da história de Trindade, como foi o caso das montagens Credo e Graça, Jesus, Segundo
16. O Grupo possui a Escola de Samba Acadêmicos de Trindade iesde 1989,

17. O FAAL é realizado no mês de agosto e abrange diferentes modalidades artísticas, tais como música, dança, literatura, teatro e artes visuais.

18. O Festival Estudantil de Teatro de Trindade normalmente ocorre no mês de maio e reúne dezenas de grupos teatrais de escolas do município. "No Festival, escolas públicas e particulares montam seus espetáculos, assistidos pelo Grupo Desencanto, que promove oficinas com alunos de cada "entidade participante". Jacinto, "Festival de Teatro", Jacinto et al. Grupo Desencanto de Teatro:

19. Jacob. A santíssima Trindade de Barro Preto: história da romaria de Trindade, p. 349.

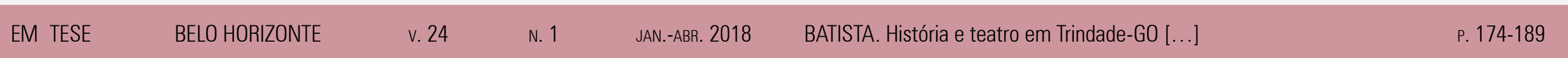


20. O texto teatral aqui utilizado é um manuscrito de Amarido Jacinto, não publicado e datado de 2009. Para citações da peça, usaremos a sigla $\mathrm{BP}$
Todo o Mundo, Pim-Pão, Padre Pelágio, Judas e Salmos. Dentre esses trabalhos, dois espetáculos passaram a integrar o repertório permanente do GDT, pela sua repercussão na comunidade, a saber, Povo da Villa de Barro Preto de Goyaz e Rua da Alegria. Ambos os textos foram escritos e encenados por Amarildo Jacinto, a partir da memória da cidade, localizada em diferentes períodos históricos.

\section{BARRO PRETO}

O enredo do espetáculo Povo da Villa de Barro Preto de Goyaz, ${ }^{20}$ levado à cena nos últimos anos, remete a episódios da história que deram início à romaria do Divino $\mathrm{Pa}$ Eterno, no antigo arraial de Barro Preto, o qual se constituiu ao redor de uma casa de oração. Este fato se situa na década de 40 do século XIX, quando o casal de lavradores Constantino-Ana Rosa Xavier teria encontrado, durante a roçagem de um pasto, uma medalha em que figura a coroação de Maria pelos três ícones da trindade cristã: Pai, Filho e Espírito Santo, objeto sagrado que então comporia o ora tório doméstico para a reza diária do terço. Próximo dali, para acolher ta mbém os vizinhos nesse ato de devoção, o casal constrói uma capela, dando início grada tivo a uma romaria. Assim, sertanejos de outras regiões começam a se reunir naquela choupana. Sobre as origens da romaria do Barro Preto, Amir Jacob rela ta que
Na mesma proporção que crescia a fama do arraial da Santíssima Trindade do Barro Preto, - pelos milagres operados pelo Divino Padre Eterno - crescia o número de romeiros que, durante todo o ano, preparavam-se para a romaria, chegando dias antes do início da novena solene. Surgiam de todos os lados, de todas as estradas, de todos os caminhos e trilhos. Vinham cantando o rosário e os benditos, ora em grupos ora isolados, em carros de boi, a pé puxando animais arreados, carregando cruzes, bandeiras e estandartes. Muitos, vendo ao longe as minúsculas torres da igrejinha, ajoelhavam-se e terminavam a difícil jornada sobre as feridas dos joelhos. ${ }^{21}$

Com a notícia de milagres, o local se torna ponto de peregrinação nas décadas seguintes, o que demanda a construção de uma capela mais espaçosa, já contando com uma réplica maior do que a da imagem encontrada, ${ }^{22}$ quando também acontece a oficialização do evento. Nos primórdios da romaria, um único padre passava pela região e apenas uma vez por ano, contudo, tempos depois, chegaria m ao lugar os padres missionários de Campininha das Flores, para celebrar missas, procissões, terços e novenas, com o objetivo de cristianizar a romaria, dado que, segundo relata Amir Jacob, "Barro Preto, naquela época, não tinha igreja, pertencia à Paróquia de Campinas, onde faziam batizados e casamentos". ${ }^{23}$
21. JACOB, A santíssima Trindade de Barro Preto: história da romaria de Trindade, p. 90.

22. A encomenda da imagem teria sido feita ao renomado artista Veiga Valle, suposto aconteciment que o texto de Amarildo Jacinto recria em cena.

23. JACOB. A santíssima Trindade de Barro Preto: historia da romaria de Trindade, p. 52. 
24. FRANÇA. As trajetórias socioespaciais dos carreiros de fé da romaria do Divino Pai Eterno em Trindade-Goiás, p. 33 .

25. JACOB. A santíssima Trindade de Barro Preto: historia da romaria de Trindade, p. 94; grifos do autor.
Com a institucionalização da romaria, que passa a se chamar Festa do Divino Pai Eterno, Barro Preto se enche de pessoas interessadas em ali se estabelecer, fato que promove o desenvolvimento local, com a iniciativa de comerciantes interessados em investir no povoado. Sobre a formação da cidade a partir da romaria, a nalisa Rames França em dissertação de mestrado:

O fluxo de pessoas para o local da 'Casa de Oração' foi intensificando de tal forma que em 1866, o casal que descobriu o medalhão de barro com a imagem santa, Constantino Xavier e Ana Rosa, construiu um novo santuário para substituir a Casa de Oração. Pouco antes, em 1854, o local já era chamado de 'Santíssima Trindade do Barropreto'. A romaria ia dando forma e conteúdo à futura cidade de Trindade, nascida da migração religiosa, um fenômeno que há muito está presente na vida humana. ${ }^{24}$

Entretanto, o fenômeno migratório também se faz acompanhar pela exploração comercial, com o estabelecimento de ranchos de dança, jogos, bebidas e prostituição. No que toca a essa questão, Jacob registra em seu livro: "com o passar dos anos, as piores inconveniências apareceram: levas de mulheres que vendiam o corpo em 'ranchos alegres', especialmente montados para esse fim, saltimbancos, jogatinas, e jagunço perigosos que vinham 'acertar contas' no meio da multidão".
Por sua vez, os padres começam a tomar para si as generosas doações dos romeiros, como identificamos neste comentário de uma personagem: "Quem tá ganhando mesmo são os Padres, minino de Deus, é cavalo, cabrito, boi, dinheiro, brinco, anel, um trem de louco e eles ficam com tudo, num reparte nada com ninguém...”. ${ }^{26} \mathrm{Na}$ verdade, o clero chega a representar uma a meaça ao poderio local, principalmente quando o bispo ordena que a organização da romaria e a arrecadação da sua renda seja m comandadas pelos padres, que são expulsos por agitadores e inimigos da igreja, tendo à frente um coronel, justamente o chefe que presidia a comissão do evento e recolhia as doações para o seu bolso. Com relação a tais conflitos de interesses, Jacob põe em relevo a figura do coronel Anacleto:

Para levarem adiante o processo de cristianização da romaria, o Bispo e os missionários redentoristas tiveram que batalhar contra um bulhonista, Coronel Anacleto Gonçalves de Almeida, - que dominava o Arraial de Barro Preto e que se intitulou 'católico, apostólico, mas não romano', 'dono' da Romaria de Trindade e administrador do cofre do Santuário. ${ }^{27}$

Como retaliação à ação do coronel, o bispo ordena que os padres saiam do arraial, interdita o lugar e excomunga a romaria do Divino Pai Eterno. "O lugar deixava de ser sagrado. O interdito era uma excomunhão, uma oração de maldição que declarava a ausência de Deus naquele
26. BP, p. 5.

27. JACOB. $A$ santissima Trindade de Barro Preto: história da romaria de Trindade, p. 178; grifos do autor.

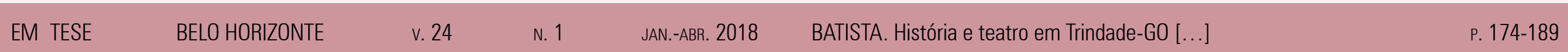


28. JACOB. A santíssima Trindade de Barro Preto: história da romaria de
Trindade, p. 204; grifos do autor.

29. JACOB. A santíssima Trindade de Barro Preto: história da romaria de Trindade, p. 206; grifo do autor.

30. FRANÇA. As trajetórias socioespaciais dos carreiros de fé Eterno em

Trindade-Goiás, p. 59 luga ${ }^{2}{ }^{28}$. Em seguida, o bispo tenta levar a imagem para Campinas, porém é impedido pelo povo, orquestrado pelos representantes da liderança local. Assim, "Vendo o bispo que se retrocedesse, e colocasse a imagem novamente no altar, era perder sua autoridade, mas avançar era morte certa: Entregou ao Pe. Wendel a sagrada imagem e agiu com 'sabedoria': desmaiou". ${ }^{29}$ Sobre essas desavenças que fizeram história em Trindade, Rames França esclarece em seu trabalho de mestrado:

Além das discórdias entre os padres e os coronéis que comandavam a irmandade por conta da administração dos recursos, a romaria também era objeto de discórdia com os padres, só que dessa o problema era com o povo, ela era a preferida pelos devotos, pois era, nada mais, nada menos que a própria criação do povo. Antes que os coronéis entrassem e constituíssem a irmandade, antes que a Igreja reconhecesse a festa, a romaria já existia e por vontade exclusiva e única dos devotos ao santo. ${ }^{30}$

Dada a impopularidade da festa nos anos seguintes, que passa a contar com um número reduzido de romeiros, o coronel que havia chefiado o confronto com o bispo pede perdão, gesto que leva o bispo a retirar a excomunhão, e os padres a retornarem a Barro Preto, atendendo a súplicas da comunidade que, sem o clero, não conseguia atender às demandas. ${ }^{31}$ Então, o povo comemora: "Agora os padre vêm! Acabou, acabou a excomunhão da Festa Grande. O Bispo de Goyaz retirou a excomunhão, Coronel pediu perdão e o governador intercedeu. Depois de 2 anos sem os padres, a Festa Grande volta com força total. Êêêêta trem bão sô!" 32 . Com valores ca tólicos cada vez mais arraigados, um episódio curioso a notar é o óbito do professor Moysés Baptista, alguém que contribuiu significativa mente para a instrução na vila, porém teve proibido o seu sepultamento no cemitério (então uma instituição religiosa), simplesmente pelo fato de ter sido um educador de base positivista Sobre esse intelectual à frente de seu tempo, Lúcio Arantes e Bento Fleury dizem em uma crônica de Beco dos aflitos:

Esse positivista era polêmico e alta mente aca tado pelo povo, entrando sempre em atrito com o poder dominante e principalmente com a Igreja, na figura dos Padres Redentoristas. Anti-bulhonista, com características anarquistas, o professor Moysés Baptista de Abreu marcou época na Trindade antiga, figurando na história como o seu principal agente da discordância. ${ }^{33}$

Mais de meio século depois do achado do medalhão, a vila se encontra bastante populosa, com uma paisagem transformada, fato que evidencia a necessidade de autonomia política. "A romaria ia dando forma e conteúdo à
31. Conforme narrado em uma crônica de Lúcio Arantes e Bento Fleury: "Impedidos de ficar no Barro Preto, fixaram residência em Campininha das Flores, fazendo desobrigas na Igreja do Pai Eterno e por epoca da Romaria. O Bispo, enfurecido com a questấo das rendas repartidas, criou atrito com o Coronel Anacleto, excomungou a Romaria e transferiu a sede do Bispado para Uberaba no sertão da Farinha Podre. Só três anos mais tarde é que a situação se normalizou e os Padres voltaram "Onde está o dints, Onde está o dinterio?

32. BP, p. 7.

33. ARANTES; FLEURY, "Cruz das Almas - A vingança do morto", Beco dos aflitos, p. 50.

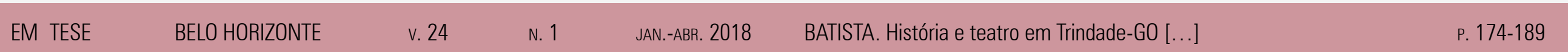


34. FRANÇA, As trajetórias socioespaciais dos carreiros de fé Trindade-Goiás, p. 33.

35. BP, p. 10-11

36. D. Eduardo Silva, bispo de Goiás no periodo, traz em sua autobiografia tal informação sobre o Cel. Anacleto: "Em caminho de Bela Vista para Campininhas veio ao meu encontro o Padre Spaeth, superior do convento, o qual chegando à fala, exclama todo apavorado: Revolução, senho bispo, revolução!!! Contou-me então que um tal Coronel Anacle homem grosseiro, inculto, sem religiano, e que anos atrás havi crobata, se arvorara mandara fazer a novena Bispo, de Barro Preto [...]". apud JACOB, A santíssima Trindade de Barro Preto: história da romaria de

Trindade, p. 198-199.

37. BP, p. 13 futura cidade de Trindade, nascida da migração religiosa, um fenômeno que há muito está presente na vida humana”. ${ }^{34} \mathrm{O}$ narrador do espetáculo assim resume as alterações ocorridas em Barro Preto:

O tempo foi passando, o progresso foi chegando, Barro Preto foi crescendo e tudo aumentando. Veio gente importante de tudo quanto é lado. A Villa já tinha posto de gasolina, venda, armazém, e professor e ta mbém tinham muitos problemas, no ano de 1920, Barro Preto não era a mesma de Constantino e Ana Rosa [...]. ${ }^{35}$

Com uma ocupação desordenada e uma população cada vez mais numerosa, o lugar finalmente recebe autorização do governador para se elevar à condição de município. Nas últimas cenas, o problema que surge é a falta de um prefeito, cargo para o qual se habilita o coronel Anacleto, figura que, segundo se conta, havia chegado à cidade como artista de circo. ${ }^{36}$ No quadro final, remonta-se à decisão pelo nome da nova cidade, e os presentes acorda $\mathrm{m}$ em aludir às três divindades do medalhão encontrado; então o corone encerra a questão: "Será chamada de Trindade, município de Trindade, em honra ao Pai Eterno e homenagem à Constantino Xavier e Ana Rosa, e a todo o povo que deu início à devoção, à fé e à Romaria” ${ }^{37}$ A propósito, é importante registrar o que o folder do espetáculo explicita sobre a interpretação da história da romaria de Trindade e de seus pioneiros pelo grupo tea tral:

Barro Preto surgiu em meados de 1840 nos registros históricos goianos como arraial subordinado à Campininha das Flores. Nasceu da fé e da piedade do casal Constantino Xavier e Ana Rosa, oleiros que encontraram um medalhão contendo a imagem da Santíssima Trindade, dando assim início à Romaria do Divino Pai Eterno. Em 1910 passou à condição de distrito e em 16 de julho de 1920 ganhou sua autonomia política que foi acelerada pela transferência da Capital do estado de Goiás para Goiânia, em 1937. Povo da Villa de Barro Preto de Goyaz conta a história de um povo simples, humilde e possuidor de uma grande fé a ponto de fazer desta terra no coração do nosso País, a casa do Pai Eterno. ${ }^{38}$

Com essa visão, Povo da Villa de Barro Preto de Goyaz reconta alguns dos principais fatos que deram início à romaria de Trindade, e, por conseguinte, à própria cidade. Com efeito, é proveniente dessa festa religiosa instituída pelo povo vilabarrense que vemos nascer o município de Trindade. Como sustenta a pesquisadora Maria Idelma D’Abadia:

É a partir da romaria, portanto, que nasce Trindade, cujo embrião foi o aglomerado de Barro Preto, local onde foi encontrado o medalhão que daria início à romaria, ou seja, a
38. Folder do espetáculo Povo da Villa de Barro Preto de Goyaz. "Pingos de nossa história". s.d. Acervo pessoal. 
39. D'ABADIA, Diversidade e identidade religiosa: uma leitura espacial dos padroeiros e seus festejos em Muquem, Abadiânia e Trindade-GO, p. 120

40. O texto da peça aqui utilizado e um manuscrito de Amarido Jacinto, não publicado e datado de 2004. Para citações de Rua da Alegria, usaremos a sigla RA. um movimento pendular caracterizado pela religiosidade e busca do sagrado por parte do homem sertanejo de Goiás. A origem das cidades está relacionada às necessidades de compartilhamento e, por isso, os rituais festivos precedem a própria cidade $\left[. . . .^{39}\right.$

Em cena, reconhecemos figuras que fizeram a história de Trindade, como o casal Constantino-Ana Rosa Xavier, o coronel Anacleto Gonçalves de Almeida, o bispo Dom Eduardo Duarte da Silva, o professor Moysés Baptista, dentre outras pessoas representativas, sem que se incorra, contudo, em uma leitura simplificadora ou ingênua dessas personagens. Desse modo, se a encenação de Amarildo Jacinto, por um lado, reconhece a honesta devoção do casal fundador da romaria, por outro, também retrata a impostura de membros do clero nas décadas seguintes. Nesse aspecto, deparamo-nos, ainda, com outras iniquidades, seja o despotismo de um bispo, seja o mandonismo de um coronel, seja, ainda, a exploração comercial de uma festa religiosa, cujas origens tinham como único intuito um ato de devoção.

\section{RUA DA ALEGRIA}

Juntamente com Povo da Villa de Barro Preto de Goyaz, a temática de Rua da Alegria ${ }^{40}$ integra a vertente de espetáculos do GDT baseados em eventos e sujeitos passados do município. A propósito, reporta uma personagem nas cenas finais de Povo da Villa de Barro Preto de Goyaz: "imagina só, a Vila já tinha até cabaré e ficava na Rua da Alegria". ${ }^{41}$ Fato é que, nesta mencionada via, se localizava um prostíbulo, frequentado por homens de renome da sociedade, que oferecia o único entretenimento da cidade, com mulheres, jogos de bilhar, sinuca, bebidas, e servia a mais conhecida galinhada da região, um típico prato goiano. A paisagem trindadense desse período é assim descrita em uma crônica: "A vida social de Trindade nos anos 30 era pouco intensa, consistindo em visitas, bailes em casas particulares pois não havia clubes. As notícias chegava $m$ através de jornais e revistas e através dos famosos 'representantes comerciais' transmissores de cultura". ${ }^{22}$ Nesse a mbiente, transcorre a ação de Rua da Alegria, situada nas primeiras décadas do município, segundo narra o curinga do espetáculo na seguinte alusão à sociedade trindadense:

Rua da Alegria, você já ouviu falar. Historicamente não existe, mas na memória de muitos, ah! Que saudade da Rua da Alegria. Curioso, hein? Vou lhe contar: Rua da Alegria era a rua dos prazeres, das moças de vida fácil, onde os rapazes, os senhores, os doutores iam se divertir. As moças de família eram proibidas pelos pais de passarem por aquela rua, acho que tinham medo de serem pegos no flagra (rá, rá, rá). ${ }^{43}$

Na casa de Da Maria Pereira, "dona da melhor galinhada de Trindade", como é conhecida, acompanha-se grande
41. BP, p. 11

42. ARANTES; FLEURY, "Trindade, anos 30 , gente, hábitos e costumes", Beco dos aflitos, p. 162; grifo dos autores.

43. RA, p. 3-4; grifo nosso
EM TESE
BELO HORIZONTE
v. 24
N. 1
JAN.-ABB. 2018
BATISTA. História e teatro em Trindade-GO [...]
P. $174-189$ 
algazarra, em meio a bebidas, piadas e expressões maliciosas das profissionais do sexo, que ali se produzem para a chegada de seus clientes, logo mais tarde. Próximo do cabaré, no largo da matriz, duas senhoras, Ambrosia e Filomena, autoprocla mam-se "moças de família", e, demonstrando ares bea tíficos de ilibada moral, exorcizam o "lugar do pecado" com os seus crucifixos, águas bentas, terços, bíblias e rezas No entanto, qua ndo se veem tão perto daquele lascivo ambiente, não resistem à própria curiosidade, e passam a assistir ao movimento à espreita. A seguir, a função se inicia na casa de $\mathrm{D}^{\mathrm{a}}$ Maria Pereira, mas, inesperadamente, a polícia chega ao local, e os clientes fogem a medrontados, ao mesmo tempo em que são espionados por Ambrosia e Filomena a poucos metros dali, não sem volúpia ao ver tantos homens nus. Em seguida, as duas senhoras se retiram contra riadas por terem contemplado aqueles rapazes correndo por tão poucos minutos. Com referência à Trindade dessa época, com as suas comadres, fofocas, recalques, rapazes, desejos, hormônios e anseios dos rapazes, narra o curinga:

Naqueles tempos era assim, as mexeriqueiras estavam em todos os lugares mas também, a tal TV era coisa quase rara. A Rua da Alegria era praticamente o único divertimento que Trindade tinha, os rapazes ficava $m$ loucos pra chegarem aos 18 anos, fazerem suas identidades e ficarem à vontade na

famosa Rua. ${ }^{44}$
Em quadros que se alternam entre o prostíbulo, a igreja e as "casas de família", mostram-se, alternadamente, a rotina das chamadas "mulheres de vida fácil", o moralismo preconceituoso da sociedade, bem como a afirmação da macheza dos pais para com os seus filhos, que, a partir de certa idade, são coagidos a frequentar a afamada casa de prostituição. Pais e filhos se confrontam porque alguns destes, apesar de já terem chegado à puberdade, alega m não ser funcional para eles o que parecia ser para os seus pais. Julinho comenta com o pai sobre mudanças no seu corpo, então ouve-se: "Georgina nele, que o danado vira home"; ${ }^{45}$ por sua vez, Luizinho rela ta ao pai que já tentou se relacionar intima mente com uma daquelas mulheres, mas "não funcionou", o que leva o pai a procurar benzedeira; em outro quadro, Nelinho argumenta com o genitor que já foi à casa de $\mathrm{D}^{\mathrm{a}}$ Maria Pereira, tentou, porém, "não conseguiu”, e, ante a tentativa malograda, quer mostrar que o "método" do pai é ultrapassado.

$\mathrm{Na}$ sequência, as prostitutas vão a uma procissão e são rechaçadas por Ambrosia e Filomena. Neste momento da peça, cabe destacar uma reflexão de $\mathrm{D}^{\mathrm{a}}$ Maria Pereira que denuncia a situação dessas mulheres frente à sociedade da época, na seguinte passagem: "Meninas, as pessoas não nos compreendem, vocês sabem disso, muitas de vocês vieram para cá, nunca estudaram, nunca tiveram oportunidade

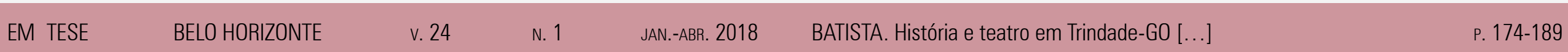


47. "Prostitutas famosas em Trindade foram Sinhaninha Bico Roxo, Benedita Tatu, Luzia, Hozana, Elza, Zanita, Filhinha, Ana do Bobo, Maria Pepé, Bastiana Linguiça, Maria Pepe, Bastiana Linguiça, "Balaio de puta": território da prostituição, miséria e exclusão no espaço trindadense [online]; grifo do autor.

48. RA, p. 7. alguma, porque a própria sociedade contribuiu para que isso acontecesse". ${ }^{46}$ Os nomes dessas mulheres, a começar por $\mathrm{D}^{\mathrm{a}}$ Maria Pereira, são fictícios, assim, as prostitutas que viveram na Trindade de antanho recebem na peça pseudônimos, como Clarice, Brotojela, Cla rete, Georgina, Paulina, Lurdinha e Paulete. ${ }^{47}$ Mas, apesar dessa opção dra matúrgica e, claro, também ética, não se deve passar despercebido que essas mulheres realmente existiram, e fazem parte da memória extraoficial do município de origem religiosa.

Curinga: Hoje tem alegria/Tem sim senhor/Hoje tem mulherada/Tem sim senhor/e o curinga o que é/ um ladrão de mulher...Alegria, alegria, alegria, essas pobres mulheres que tentavam ser alegres para defender o seu pão de cada dia, enfrentava $\mathrm{m}$ os preconceitos de uma sociedade que nunca as aceitava. ${ }^{48}$

Conforme material de divulgação do espetáculo, a famosa rua teve início em meados de 1920, oferecendo os seus entretenimentos desde a emancipação do município. A ação da peça de Amarildo Jacinto enfoca as décadas posteriores, principalmente os anos 1970, porque é nesse período em que o prostíbulo passa a incomodar as demandas de mercado do lugar. Desse modo, o divertimento dos homens trindadenses se torna ameaçado e a meaçador, pois, com a expansão da cidade, a "Rua da Alegria", então localizada no centro, mudara o seu perfil, inclusive o comercial. Já não seria conveniente uma casa de prostituição no lugar que abarcaria agora outros perfis de consumidores, inclusive as mães, irmãs, esposas, sogras, filhas, netas, sobrinhas, cunhadas e noras dos clientes que frequentava m o lupa nar. Veja mos o momento em que o curinga se refere a tal transformação na paisagem trindadense:

Mas chegou um tempo que tudo foi mudando, as boites, as zonas, os puteiros, os balacos bacos daquela rua já não eram os mesmos, a cidade foi crescendo, começou a nascer a feira da cidade, e adivinhem onde a bendita feira, na Rua da Alegria... Bom, então as mulheres da Rua da Alegria começaram a incomodar demais. O espaço para essas mulheres da vida começou a ficar pequeno, começaram também a perder clientes e mais clientes... ${ }^{49}$

No desfecho da peça, o juiz de direito da cidade determina a retirada da casa de D. ${ }^{\text {a }}$ Maria Pereira para um morro distante, fato que é lamentado por alguns e comemorado por outros. O curinga lê o que a referida autoridade ordenou: "nenhuma boite, nenhum bordel, nenhum cabaré, poderá mais permanecer na Rua da Alegria, e decreta mais: de hoje em diante, todas as coisas da farra, da cachaça, da farofa e da galinhada deverão ser no morro". ${ }^{50}$ 
52. "A charrete alcunhada de 'Balaio de puta' que tinha o seu ponto ao lado da Rodoviária de Trindade, inaugurada em 1970, e que transportava as meretrizes que foram expurgadas do centro antigo da cidade para o chamado 'Morro"'. Fleury, "Balaio de puta" território da prostituição, miséria exclusăo no espaço trindadense lonlineli grifos do autor.

53. VIEIRA, Grupo Desencanto de Teatro apresenta Rua da Alegria [online].
Assim, acabou a "Rua da Alegria", transcorre o intervalo de alguns anos e os homens comentam: "o que importa é que fomos felizes na Rua da Alegria..."/ "Isso mesmo, o que importa é a história, lembranças de um tempo que nós vamos ter para contar sempre" ${ }^{51} \mathrm{Na}$ sequência, Filomena e Ambrosia ta mbém lamentam a retirada do cabaré, pois nunca mais volta ram a ver aqueles homens com tão pouca roupa. Diga-se de passagem, Filomena confidencia à comadre que realizou o seu sonho de andar na carruagem chamada "balaio de puta", ${ }^{52}$ e, ao avistar Da Maria Pereira, hilariamente corre para pedir-lhe um autógrafo. A coreografia inicial do teatro de revista, a dança do can can sugerida como entreato, bem como a marchinha de carnaval do epílogo em meio a confetes conferem leveza e humor à temática. Nesse sentido, destacamos, conforme Sérgio Vieira, "O texto leve, às vezes picante e mordaz, aqui e ali, [...] compõe um espetáculo alegre, que faz rir, informa ta mbém, e no geral, é sim uma diversão ga rantida. E ainda por cima, quem assiste à Rua da Alegria fica conhecendo fatos interessantes da história dos trindadenses" ${ }^{33}$ Sobre o tema recriado no palco, indica o folder do espetáculo:

O espetáculo Rua da Alegria é o resultado de uma pesquisa intensa sobre essa famosa rua que teve início em meados de 1920 e o seu fim em 1972, onde funcionava a zona de baixo meretrício da cidade de Trindade. Hoje, é a famosa rua Coronel Anacleto, que outrora abrigou cabarés, bares e restaurantes, em uma época onde televisão era um caso raro, e onde os homens iam se divertir. Com o crescimento da cidade, a rua acabou ficando no centro, causando transtorno e incomodando muitas famílias, obrigando o juiz da cidade a baixar um Decreto transferindo a famosa rua para um local mais distante 'o Morro' hoje denominado Morro do Samara, onde ainda existem muitas casas de diversão. ${ }^{54}$

Diferentemente de Povo da Villa de Barro Preto, a encenação de Rua da Alegria traz à nossa vista um lugar apagado da história de Trindade do qual bem poucos parecem se recordar, pois "são coisas que a história oficial não registra da 'terra santa da devoção'!". ${ }^{55}$ A "Rua da Alegria” está na memória de alguns daquele tempo que ainda vivem entre nós, ou de seus descendentes, ${ }^{56}$ mas segue invisível na história no máximo, se encontram anedotas e relatos pessoais a respeito. Nas fontes históricas aqui consultadas, não há alusão ao lugar, excetuando-se uma breve passagem em crônica de Arantes e Fleury: "E a Rua Cel. Anacleto após o cemitério (onde hoje é o mercado municipal) era conhecida por 'Rua da Alegria', zona de prostituição" ${ }^{57} \mathrm{O}$ texto de Amarildo Jacinto conta a vida de mulheres que nada tinham de "vida fácil" e reconstitui o olhar com que eram vistas pelo comportamento conservador/moralista da sociedade da época. Talvez por isso, não aparecem na memória oficial da
54. Folder do espetáculo Rua da Alegria. s.d. Acervo pessoal.

55. Fleury. "Balaio de puta": território da prostituição, miséria e exclusão no espaço trindadense [online] grifo do autor.

56. O espetáculo Rua da Alegria foi criado com base em relatos orais de homens que frequentavam $o$ lugar.

57. ARANTES; FLEURY. "Trindade, anos 30, gente, hábitos e

163; grifo dos autores.

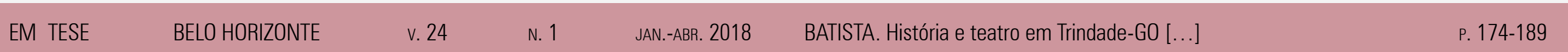


58. Fleury. "Balaio de puta": território da prostituiçâo, miseria e exclusão no espaço trindadense [online]; grifos do autor. “cidade-santuário”. Desse modo, é possível reconhecer, nos diálogos e personagens do espetáculo, os sujeitos, valores, desejos, repressões, tradições e sobretudo contradições, de uma cidade que, segundo diagnóstico de Bento Fleury,

[...] sob a égide religiosa, que, ao mesmo tempo, mascarou um mundo de intensos preconceitos em relação às diferenças sociais, notadamente as prostitutas que foram relegadas a um território alcunhado de 'Morro' em zona distante do centro da cidade, no intuito de 'sanear' moralmente uma sociedade que, sabemos, também se marcou pela hipocrisia, já que, à sombra da religião católica, promoveu eugenias absurdas e atrocidades inacreditáveis [...]..$^{58}$

\section{EPÍLOGO ACERCA DO “DESPERTAR DO ENCANTO”}

Com os espetáculos aqui estudados, foi possível verificar como o teatro do Grupo Desencanto reconstitui sujeitos, episódios, locais e conflitos da história da cidade de Trindade. Pela sua essência representativa, a encenação teatral dá a ler e a ver uma realidade já vivida, ao mesmo tempo em que possibilita revisarmos a perspectiva divulgada pela história oficial. Com efeito, a arte teatral, na efemeridade em que se dá, permite questionarmos o que foi lembrado, por que foi lembrado, e junto a isso, o que foi esquecido e por que foi esquecido. Afinal, "Faz parte do exercício do poder ocultar a diferença, a contradição, decidindo o que deve ser lembrado, como deve ser lembrado e, em contrapartida, o que deve ser esquecido". ${ }^{59}$ Como arte, o teatro é capaz de dar luz e forma a sujeitos relegados, enfocando o desprezado e desmistificando o consagrado pela história. São essas características que reconhecemos nos diálogos, nas ações, na roteirização das cenas e no caráter das personagens dos espetáculos Povo da Villa de Barro Preto e Rua da Alegria.

No espetáculo Povo da Villa de Barro Preto, acompanhamos, em cenas breves, transformações definitivas na história de Trindade em um curso aproximado de oitenta anos. De uma vila que se forma ao redor de uma singela casa de oração nos a nos 40 do século XIX, à emancipação deste lugar como cidade, já cheia de gente e conflitos, no início do século XX Identifica mos, no tratamento que o espetáculo dá à história, que, por importantes que sejam os coronéis, os padres e os comerciantes ali estabelecidos, o protagonista, na verdade, é o povo, porque é dele que se origina a romaria do Pai Eterno, assim como é desta que surge a cidade. Aliás, no que diz respeito à produção do espaço urbano de Trindade, explica a geógrafa Maria Idelma D’Abadia:

De um cenário em que se configura o sagrado, passa-se a outros que, com o tempo, vão sendo incorporados ao centro
59. VIEIRA; PEIXOTO; KHOURY. $A$ pesquisa em história, p. 27.

$\begin{array}{lllll}\text { EM TESE } & \text { BELO HORIZONTE } & \text { v. } 24 & \text { N. } 1 \quad \text { JAN.-ABr. } 2018 \quad \text { BATISTA. História e teatro em Trindade-GO [...] } & \text { P. 174-189 }\end{array}$


60. D'ABADIA, Diversidade e identidade religiosa: uma leitura espacial dos padroeiros e seus Trindade-GO, p. 121. de peregrinação. Ir ao santuário, fazer-se romeiro, leva necessariamente a novas formas de uso, produção e apropriação da festa. À cidade romaria, à cidade santuário, à hierópolis, vão se justapondo outras significações e atribuições, tais como atividades políticas, culturais e econômicas que permeiam esse universo mítico da romaria. ${ }^{60}$

Em Rua da Alegria, por sua vez, deparamo-nos com mulheres excluídas da sociedade, seja pelo fato de serem prostitutas, seja pelo banimento posterior para um morro. Referimo-nos aqui a mulheres que fizeram a história de Trindade, pelo menos no período dos a nos 1920 aos a nos 1970, as quais deixaram marca em um logradouro da cidade, cujo título Rua da Alegria, na verdade, mais parece ironizar a tristeza de ser eliminada da sociedade. A Rua da Alegria se tornou Rua Cel. Anacleto, porque este sim deve ser lembrado pela história como primeiro prefeito do município. Por sinal, o professor Bento Fleury contribui com uma reflexão bastante oportuna desse expurgo social: "A cidadania foi negada quando as prostitutas foram expurgadas da Rua da Alegria para o Morro, então muito distante do centro da cidade, [...]. Não houve uma escolha, mas, sim, uma imposição, como se uma limpeza da cidade do seu 'lixo humano"”. ${ }^{61}$
Em vista dessas considerações, reconhecemos, nos dois espetáculos, o ideário do Grupo Desencanto de "despertar do encanto", isto é, de despertamento para a realidade. Ambos os espetáculos nos convidam a sair do "encanto" ilusório do status quo da história, provocando-nos a repensar o que nos coloniza o imaginário em forma de conteúdo histórico. Paradoxalmente, este nos parece ser o encanto do grupo: conseguir nos emocionar e nos divertir, na medida em que nos transporta para um mundo fictício capaz de desnudar a realidade em forma de linguagem teatral, ou, em outras palavras, com a máscara própria do tea tro, desmascarar discursos tidos como verdadeiros.

\section{REFERÊNCIAS}

Arantes, Lúcio; Fleury, Bento. Beco dos aflitos. Brasília:

Thessaurus, 200

Aristóteles. Poética. In: Ética a Nicômaco; Poética. Tradução de Eudoro de Souza. (Col. Os pensadores). São Paulo: Nova Cultural, 1987. p. 197-229

Arrais, Tadeu. Seis modos de ver a cidade. Goiânia: Cânone Editorial, 2017.

Campos, Emerson: falcão, Luiz Felipe. Percorrendo cidades na contemporaneidade In: Ramos, Alcides F et al. (Org). Temas de história cultural São Paulo: Hucitec, 2012 p. 83-92.
61. Fleury, "Balaio de puta": território da prostituição, miséria e exclusão no espaço trindadense [online]. 
D'Abadia, Maria Idelma Vieira. Diversidade e identidade religiosa: uma leitura espacial dos padroeiros e seus festejos em Muquém, Abadiânia e Trindade-GO. Jundiaí: Paco Editorial, 2014.

Fleury, Bento. "Balaio de puta": território da prostituição, miséria e exclusão no espaço trindadense. Trindade-GO: Academia Trindadense de Letras, Ciências e Artes, 11 nov. 2017. Disponível em: <http://www.atleca.com.br/publicacao.php?id=1512>. Acesso em: 15 dez. 2017.

\section{França, Rames Divino. As trajetórias socioespaciais dos}

carreiros de fé da romaria do Divino Pai Eterno em TrindadeGoiás. 2008. 114 f.: il. Dissertação (Mestrado em Geografia) Instituto de Estudos Socioambientais da UFG, Goiânia, 2008

Jacinto, Amarildo et al. Grupo Desencanto de Teatro: especia 25 anos. Sociedade Cultural Desencanto: Trindade-GO, 2012.

Jacób, Amir S. A santíssima Trindade de Barro Preto: história da romaria de Trindade. 3. ed. Trindade-GO: Ed. PUC Goiás, 2010

Pesavento, Sandra J. História \& história cultural. 3. ed. Belo Horizonte: Autêntica Editora, 2014.

- Muito além do espaço: por uma história cultural do

urbano. In : Estudos históricos Rio de Janeiro, vol. 8, n. 16, p. 279-290, out. 1995

Vieira, Maria do Pilar de A.; Peixoto, Maria do Rosário da C.;

Khoury, Yara Maria A. A pesquisa em história. 4. ed. São Paulo:

Ed. Ática, 2006
Vieira, Sérgio. Grupo Desencanto de Teatro apresenta Rua da Alegria. Trindade: Blog do Sérgio Vieira, 07 abr. 2017. Disponível em: <http://www blogdosergiovieira.com.br/2017/04/grupo-

desencanto-de-teatro-apresenta.html>. Acesso em: 14 abr. 2017.
Recebido em: 29-06-2018. Aceito em: 10-09-2018 